\title{
The Use of Models as a Form of Written Feedback to Secondary School Pupils of English
}

\author{
NOELIA MARTÍNEZ ESTEBAN \\ JULIO ROCA DE LARIOS* \\ Universidad de Murcia
}

Received: 20 July 2010 / Accepted: 29 October 2010

\begin{abstract}
The present study investigated how noticing is related to composing and subsequent feedback processing in individual and collaborative EFL writing. Participants were Spanish secondary school pupils at a lowintermediate proficiency level who completed a three-stage writing task that included writing a picture-based story (Stage 1), comparing their written texts with two native-speaker models (Stage 2), and attempting subsequent revisions (Stage 3). The results indicate that the students noticed mainly lexical problems at the writing stage but could only find a few solutions to those problems in the models provided. However, the comparison with the models allowed them, especially those who wrote collaborativelly, to notice a large number of features related to the content of the pictures and the linguistic means used to express that content. They were also found to incorporate a reasonable number in subsequent revisions. A number of implications from these findings for research and pedagogy are suggested.
\end{abstract}

\section{KEYWORDS:}

noticing, written feedback, composing, second language writing, models, collaborative writing, second language acquisition.

\section{RESUMEN EN ESPAÑOL}

El objetivo de este estudio es investigar la relación entre atención, escritura y feedback durante la redacción individual y colaborativa de textos en inglés como lengua extranjera. Los participantes eran alumnos españoles de enseñanza secundaria con nivel de competencia intermedio-bajo que completaron una tarea de redacción en tres etapas: escritura de una narración a partir de unos dibujos (Etapa 1), comparación de los textos escritos con dos modelos escritos por hablantes nativos (etapa 2) y revisión posterior de los textos originales (etapa 3). Los resultados indican que los estudiantes repararon en errores principalmente de tipo léxico durante la escritura de la narración, pero que sólo pudieron encontrar unas pocas soluciones a esos problemas en los modelos proporcionados. Sin embargo, la comparación con los modelos les permitió, especialmente a los que trabajaban en colaboración, percatarse de un amplio número de elementos relacionados con el contenido de los dibujos y los medios lingüísticos utilizados para expresar tales contenidos, así como incorporar un número razonable de estos elementos en las revisiones posteriores. De acuerdo con estos resultados, se sugieren diversas implicaciones para la docencia y la investigación.

\section{PALABRAS CLAVE}

Atención, corrección de trabajos escritos, composición por escrito, redacción en segundas lenguas, modelos, redacción colaborativa, adquisición de segundas lenguas

*Address for correspondence: Julio Roca de Larios, Departamento de Didáctica de la Lengua y Literatura, Facultad de Educación, Campus de Espinardo, Murcia 30010, Spain. Tel: +34 868 887123; Fax: + 34868 883646; e-mail: jrl@um.es 


\section{INTRODUCTION}

Given the communicative redundancy and lack of saliency of much L2 input data (Schmidt, 2001), intentional focused attention -i.e., noticing- is nowadays becoming widely accepted as a prerequisite for L2 learning to take place (Hanaoka, 2006, 2007). As suggested by Qi and Lapkin (2001), the significance of this concept for second language acquisition can be understood from such claims as "those who notice most, learn most" (Schmidt \& Frota, 1986: 313), or "no noticing, no acquisition” (Ellis, 1995: 89). Schmidt (2001), in particular, has stressed the role played by noticing in language learning through the assumption that "SLA is largely driven by what learners pay attention to and notice in target language input and what they understand the significance of noticed input to be” (pp. 3-4).

Some support for these ideas can be found in different fields of inquiry (see Sachs \& Polio, 2007). These range from findings about the superiority of explicit versus implicit instruction in the acquisition of L2 forms (Norris \& Ortega, 2000) or claims that form-focused instruction is linked to higher learning rates and ultimate achievement (R. Ellis, 2001) to arguments about the impact that explicit knowledge and attention to form can have on implicit language learning (N. Ellis, 2005). Along these lines, studies on oral interaction have found that the effectiveness of "recasts" can be enhanced when learners are given either cues about their corrective nature or the possibility of comparing the recast to the original erroneous utterance (Loewen \& Philp, 2006). Collectively considered, these studies seem to indicate that prompting learners to become aware of certain aspects of language may facilitate their L2 development (Ellis, 2001; Sachs \& Polio, 2007).

Noticing in writing has largely been examined by means of descriptive studies (see Manchón, in press a and b, for a review), but there are comparatively fewer investigations that have looked at the role of noticing in L2 composing and subsequent processing when specific linguistic items are not targeted in the feedback provided (Adams, 2003; Qi \& Lapkin, 2001; Swain \& Lapkin, 2002; Tocalli-Beller \& Swain, 2005). With the intention of shedding further light on this issue, the present study attempts to investigate (i) what learners, (working individually or in collaboration) notice when they compose and when they compare their written texts to native-speaker models, and (ii) what effects such noticing has on their subsequent revisions.

In order to situate the study in the relevant literature, this is reviewed next. First, the arguments in favour of output as an essential process in promoting noticing will be briefly described. The role played by feedback in writing as a specific output modality will be ascertained and this will be followed by a review of a number of theoretical, empirical and practical arguments that find fault with traditional forms of written corrective feedback. The learning potential of alternative forms of feedback, such as reformulation and modelling, will 
then be emphasized and the need for the study of models in connection with individual and collaborative writing will be discussed. Finally, the empirical study will be fully reported.

\subsection{Output and noticing}

Traditionally, research on noticing in second language acquisition has been associated with input. Accordingly, noticing has been defined as the intake of grammar that occurs when learners pay conscious attention to input, and characterized as the first stage of language acquisition or the gateway to subsequent learning (Batstone, 1996). However, as suggested by Qi and Lapkin (2001), “there are other forms of intake that do not derive from input but are generated in output that may also be significant for L2 acquisition” (p. 279).

Up until the 1980s the word "output" was used to indicate the outcome, or product, of the language acquisition process. Output was not considered a way to create knowledge but rather a process in which learners engage to strengthen form-meaning mappings already established in their interlanguage. However, since Swain (1985) proposed the "output hypothesis", the production of language has come to be seen as serving several functions in the process of second language learning (de Bot, 1996; Gutiérrez, 2008; Izumi, 2003; Muranoi, 2007; Shehadeh, 2002). One of these functions, the noticing function of output, is based on the attested fact that, when generating language, learners may encounter gaps between what they want to say and what they are able to say, and so become aware of what they do not know or know only partially in their target language. This awareness of their own linguistic limitations ("noticing the hole") may also trigger in them the need to find out about their L2, thus facilitating more noticing in subsequent processing of target language input which may appear as feedback ("noticing the gap”). Writing, as a language-related modality that requires the production of output, may consequently allow learners to notice differences between their interlanguage and the target language when they receive corrective feedback.

\subsection{Limitations of traditional forms of feedback on writing}

Feedback on writing, then, should provide learners with opportunities to focus their attention on form and help them make comparisons between their own productions and the target language so that they may subsequently produce correct forms (Sachs \& Polio, 2007; Storch \& Wigglesworth, 2010). However, various theoretical and empirical limitations have been suggested as to the effectiveness of feedback when it is given in the form of error correction. From the theoretical angle, Truscott (1996), for example, claimed that grammar acquisition is not a one-shot discovery and that the memorization of corrections should be considered only as a superficial and provisional activity. He even went so far as to claim that grammar correction should be abandoned because it may lead learners to take fewer risks in order to make fewer errors (Truscott, 2004). Although other scholars (see, for example, Ferris, 2004) 
have argued that Truscott overstated his case and recent research has attested that some forms of corrective feedback "can assist learners to develop greater control over grammatical features which are amenable to rules of thumb” (Ellis et al., 2008: 368), the value of traditional error correction for interlanguage development still remains an open question (Polio \& Williams, 2009).

Adding to these theoretical arguments, some empirical studies on error correction have reported that this kind of feedback may not be entirely effective. For one thing, the often confusing quantity of written marks involved makes it difficult at times even for experienced writers to find out what is non-target-like in their output (Hyland, 1998). In addition, the fact that corrections usually require minimal processing on the part of the learner (Hedgecock \& Lefkowitz, 1994) has led some authors to suggest that this type of feedback may not push learners to test their hypotheses in depth (Adams, 2003). Finally, the lack of clarity, accuracy or consistency one may sometimes find in teachers' corrections (Cohen \& Cavalcanti, 1990; Lee, 2004), the occasional lack of sensitivity on the part of teachers to students' needs and ability levels (Conrad \& Goldstein, 1999; Hyland, 1998; Hyland \& Hyland, 2001) and the unfavorable conditions in which teachers often provide feedback on learners' errors (Qi \& Lapkin, 2001) have also been suggested as practical factors that may also have a negative impact on the effectiveness of written corrections.

In spite of these drawbacks, it has been attested that learners generally welcome feedback on their writing, especially from the teacher (Lee, 2004; Leki, 1991; Zhang, 1995; Zhao, 2010). Thus, if learners are to be helped to notice the gap between their interlanguage and the target language and pushed to test their hypotheses through the information they receive, other forms of fedback should be used at least as partial alternatives to traditional written corrective feedback. Two of these alternatives are reformulation and modelling, which will be discussed in the next section.

\subsection{Reformulation and modelling as feedback alternatives to traditional error correction}

Reformulation is a specific type of written feedback which is defined by Levenson (1978, in Qi \& Lapkin, 2001: 281) as “a native speaker's rewriting of an L2 learner's composition such that the content the learner provides in the original draft is maintained, but its awkwardness, rhetorical inadequacy, ambiguity, logical confusion, style, and so on as well as lexical inadequacy and grammatical errors are tidied up”. By keeping the content of the original text intact, the rewritten text provides the learner with a native writer's version that s/he can compare with his/her own draft (Qi \& Lapkin, 2001). Modelling is another type of written feedback which, as in the case of reformulation, may serve as a partial response to the problems learners experience with traditional written feedback. The difference is that, in this case, learners are provided with texts which are not intended as reformulations of their 
original written products. Models are usually written by native speakers or the teacher bearing in mind learners' age, proficiency level, etc., as well as the content and the genre of the composition, but not the texts previously produced by the students.

Different advantages usually associated with reformulation over other forms of feedback can also be applied to modelling. As errors are not explicitly signalled when texts are reformulated or modelled, learners are pushed to actively attempt to identify and understand them, a process that may hypothetically lead to deeper processing and utimately to interlanguage development (Adams, 2003; Sachs \& Polio, 2007). Reformulated and modelled texts are also supposed to provide rich sets of balanced and appropriate L2 words and structures for a given context, an aid which is absolutely necessary for EFL learners since they usually lack the exposure to those forms that native speakers have (Manchón, 2009). Another advantage is that both forms of feedback may stimulate cognitive conflict by presenting information that contradicts students' beliefs on how language works, and thus lead them to reflect and take decisions on alternative options to express their intended meanings (TocalliBeller \& Swain, 2005). However, the most important advantage of reformulation and modelling is that they may be helpful for learners to notice both similarities and differences between their interlanguage and the target language, a process that may allow them not only to reevaluate their knowledge but also to confirm it (Sachs \& Polio, 2007). In this respect, Johnson (1988) claims that, rather than giving learners a model before getting them to write their texts, there is greater psychological validity in exposing them to the L2 after the writing task has been completed. By doing so, learners will probably be on the alert to detect those features of the modelled behaviour that they themselves found problematic in their initial drafts. These assumptions, of course, involve that learners will be able to recognize reformulations or models as more target-like versions of their writing (Sachs \& Polio, 2007) and perceive them as attainable (Lázaro Ibarrola, 2009).

Empirical research attests to the abovementioned advantages of reformulation and modelling in relation to noticing (Adams, 2003; Hanaoka, 2007; Lapkin, Swain \& Smith, 2002; Qi \& Lapkin, 2001; Swain \& Lapkin, 2002; but see Sachs \& Polio, 2007, for opposing views). In Qi and Lapkin's (2001) study, two ESL Mandarin speakers at different levels of L2 proficiency engaged in a three-stage writing task: a composing stage (stage 1), a reformulation processing stage (stage 2) and a rewriting stage (stage 3). The results showed that noticing in the composing stage influenced noticing in the feedback processing stage, and that the quality of noticing had an important and direct impact on the final written product. While the study by Qi and Lapkin (2001) involved participants working individually, Lapkin, Swain \& Smith (2002) and Swain and Lapkin (2002) asked their participants, adolescent French immersion students in Canada, to write the composition and do the comparison task in pairs. Both studies reported the benefits of learning French pronominal verbs collaboratively from reformulated writing. Adams (2003) replicated and extended Swain and Lapkin's study with American university students of Spanish and found that learners who compared their original output to 
NS reformulation incorporated more target-like forms in the post-treatment output than learners who had simply repeated the task, with stimulated recall adding to the impact of noticing. As for modelling, Hanaoka (2007) carried out a study in which 37 Japanese EFL university students at two levels of L2 proficiency individually engaged in a four-stage writing task which consisted of output production (Stage 1), comparison with two nativespeaker models (Stage 2), an immediate revision (Stage 3) and a delayed revision (Stage 4). Generally, learners were found to notice lexical 'holes' in their interlanguage when producing output, and this led them to a lexically-oriented search for solutions in the two native-like models provided later. Hanaoka also found that, among the lexical features noticed from the models, those related to the problems the participants had experienced in the initial output stage were incorporated more frequently in the immediate and the delayed revisions than those features that were not related.

Although these studies have used different methodologies, one conclusion to be drawn from them is that reformulation and modelling seem to be effective tools in promoting feedback for noticing and learning linguistic forms. One may now wonder what the main differences between these forms of feedback are.

In order to investigate the purported different roles of reformulation and modelling, Hanaoka (2006) carried out a study with two ESL Japanese university students and found that each feedback type seemed to activate different but complementary attentional processes. Broadly speaking, reformulation was found to be instrumental in helping learners identify linguistic inadequacies when comparing their original texts to their reformulated, more-target like versions. This process seemed to be facilitated by the fact that, when learners faced the feedback provided to them, they already knew the meaning they wanted to convey and, precisely because of that, the cognitive comparison involved in contrasting their original texts with their reformulated versions turned out to be very useful in helping them make formfunction mappings. Models, in contrast, seemed to play the dual role of helping learners address both alternative forms and develop original meaning, as the ideas modelled in them were at times quite different from those included in learners' texts. In this sense, Hanaoka concluded, independent modelling can be taken to be more advantageous to learners than individual reformulations because the latter do not provide any alternatives to what is already correct in the original texts.

However, the results reported so far must be put into perspective. As shown above, the participants in the studies reviewed came basically from ESL university and French immersion contexts, and their L2 proficiency level ranged from intermediate to advanced. Other results might be possible if other contexts, populations and levels of proficiency were analyzed. Besides, given that the research carried out so far has indistinctively looked at writers working individually (e.g., Qi \& Lapkin, 2001) or in collaboration (e.g., Swain \& Lapkin, 2002), another issue worth examining is the relative effectiveness of individual and collaborative writing in promoting opportunities for noticing. As the exploration of the 
differential effects of each modality is one of the objectives of the present study, the main empirical findings reported by studies comparing individual and collaborative writing will be discussed in the next section.

\subsection{Empirical studies comparing collaborative and individual writing}

The main theoretical assumptions at the base of the studies comparing collaborative and individual writing are related to the quality of noticing that each condition is taken to bring about. Noticing, which is basically an individual experience, is assumed to involve a certain level of awareness that may be deepened, the argument goes, when learners talk about what they have produced. In Swain's (1995) own words, “under certain task conditions, learners will not only reveal their hypotheses but reflect on them using language to do so" (p. 132).

This use of language, or metatalk, has been described in terms of collaborative dialogue (Swain, 2000) or languaging (Swain, 2006), and is assumed to involve interactional processes of repetition, deliberation and explanation of linguistic alternatives which are supposed to lead learners to deeper levels of awareness of the relationship between meaning, form and function (Storch, 2008). Individual writing, in contrast, has been posited to be a more appropriate condition for self-initiated attention to form (Williams, 2001) and output modification (Shehadeh, 2001) within the different problem-spaces generated by writers while composing (Manchón \& Roca de Larios, 2007).

In spite of these contrasting views, there has been very little research comparing the learning potential afforded by each condition (Manchón, in press b). The few studies addressing this issue indicate that working in pairs seems to have had a positive effect on the accuracy of the texts produced by ESL students at Australian universities (Storch, 1999, 2005, 2007; Storch \& Wigglesworth, 2007; Wigglesworth \& Storch, 2009), the retention of the linguistic strings involved in the use of negative adverbs by ESL students at a New Zealand language school (Reinders, 2009), or the acquisition of vocabulary by students of Korean as a second language at a Korean university (Kim, 2008). Along with these effects, collaborative writing has also been found to give learners the opportunity of pooling their attentional and memory resources (Reinders, 2009), receiving immediate feedback while verbalizing their thoughts (Storch, 1999, 2005; Wigglesworth \& Storch, 2009), making suggestions and counter-suggestions, repeating the suggestions made and offering explanations (Storch, 2007). However, further confirmation of these reported results will only be possible if research comparing both writing conditions is accomplished in other contexts. We have attempted to broaden the empirical base of this research strand by exploring how learners from an educational context in which collaborative work is not particularly encouraged complete a feedback task through individual and collaborative writing.

To conclude, the different strands of research discussed in the previous sections have shown that there are still many open questions regarding what type of feedback elicits more 
attention to form or which task-related variables or learner-related variables may affect learners' processing of feedback as well as the effect of processing on noticing and learning. In an attempt to shed further light on these issues and given the greater applicability of models over reformulations when the ratio of students to teacher is large, the present study set out to investigate how pairs and learners working individually revised their drafts using nativespeaker models as a feedback tool. We conducted the study in a secondary school, foreign language setting, which adds, on the one hand, to previous research on adolescents in immersion programs, and, on the other, to previous work with university-level L2 learners. On the other hand, the focus on "modelling" as a form of feedback is also timely given that, to the best of our knowledge, the only two studies on modelling published so far have been those carried out by Hanaoka (2006, 2007).

\section{THE STUDY}

As mentioned above, the present study aimed to analyze the potential advantages of feedback based on native-speaker models of $\mathrm{L} 2$ writing. We intended to assess the effects of this feedback type on Spanish EFL secondary school students' individual and collaborative writing and, to that end, conceived the study as a partial replication of Hanaoka (2007) with three major methodological differences. First, Hanaoka carried out his study with students working individually while this study compared individual writing with collaborative writing (students working in pairs). Second, Hanaoka looked at students from two classes at different proficiency levels while the participants in this study had the same proficiency level. Third, Hanaoka carried out his study with undergraduates while the present study was carried out with secondary school students.

Following Hanaoka (2007), the study was guided by the following research questions:

1. What aspects of language do L2 learners notice while writing an original composition individually and in pairs? (stage 1 )

2. What do individual students and pairs notice as they compare their original texts to nativespeaker models? (stage 2)

3. What are the effects of stage 1 and stage 2 noticing on subsequent revisions? (stage 3 ).

\section{METHOD}

\subsection{Participants}

The participants were 17 Spanish students in their $3^{\text {rd }}$ year of secondary education. They were aged 15 at the time of data collection and came from an intact class. According to their 
teacher, they had a similar level of English which might be regarded as low-intermediate. Five students did the task individually while the remaining twelve were grouped in six pairs and completed the task in collaboration. The decision about who should work in pairs or individually was taken by the teacher on the basis of a number of criteria which basically revolved around the students' degree of involment in ordinary classroom activities. In her own words, the students selected for both groups could be considered as average in their level of involvement and those in the pairs got along well with each other. It may thus be assumed that the different dyad members had a good level of mutuality and equality (Storch, 2002).

\subsection{Tasks and procedures}

For the present study, a task was used to prompt learners to write a short story in response to a picture. The task was expected to provide the participants with the opportunity to notice their linguistic problems as they composed, notice the gaps between their interlanguage and the target language by comparing their own production to two native-speaker models that were provided, and, finally, rewrite their first draft after the comparison. These expectations were based on previous studies which have shown the usefulness of multi-stage tasks in eliciting those behaviours among L2 writers (e.g., Adams, 2003; Hanaoka, 2006, 2007; Qi \& Lapkin, 2001; Storch \& Wigglesworth, 2010).

The picture prompt was taken from Hanaoka (2006) and consisted of two frames which proved very useful in controlling the propositional content of the story the students were asked to write. The texts used for feedback purposes were also adopted from the same study (Hanaoka, 2006), as they were regarded by the teacher as suitable for the students. The instructions for task completion were given in Spanish and, as noticing was measured by means of note-taking, the students were allowed to take notes in the language of their choice.

The study was carried out in two days and consisted of three stages. The first and second stages were carried out on the first day, and the third stage, three days later. Before moving on to each individual stage, the students were provided with all the necessary instructions. In the stage 1 task, the students were given Sheet 1 , Sheet 2 and the pictures (See Appendix A). On Sheet 1, the students wrote a story and, on Sheet 2, they took notes on whatever problems they noticed as they wrote the story. Following Hanaoka (2007), a number of directions were written at the top of Sheet 2 with the following specific examples of notetaking in Spanish: "I don't know how to say X in English”, "I wrote X, but I'm not sure if this is correct", "what is the past tense of X?", and "I'm not sure whether the picture is describing $\mathrm{X}$ ”. At the end of this stage, students were told that they would be given two native-speaker models to help them review their original texts. Then, Sheet 2 was collected and students kept Sheet 1 and the pictures for the Stage 2 task.

In the stage 2 task, and immediately following Stage 1, the students were provided with Sheet 3 and two native-speaker models (Hanaoka, 2006) which, for ease of reference, were 
titled (A) and (B) respectively (see Appendix B). The students were asked to write on Sheet 3 whatever they noticed as they compared their original texts (Sheet 1) with the models. As in the previous stage, specific examples of note-taking were provided at the top of Sheet 3 in Spanish: “I couldn't say X, but (A) puts Y”, “(A) says X, but (B) says Y”, "I was impressed by (B)'s interpretation of one or the other picture”. At the end of this stage (Stage 2), the native-speaker models and Sheet 3 were collected and the students kept Sheet 1 and the pictures to be used in the next stage (Stage 3 revision task).

In the stage 3 task, three days later, the students were asked to rewrite their texts. They were provided with their original texts on Sheet 1 , the pictures and Sheet 4 , on which they were asked to rewrite their original composition.

\subsection{Data Analysis}

In order to investigate what aspect of language the students noticed, it was necessary to code into categories the problematic features noticed in Stage 1 (PFNs), the features noticed in Stage 2 (FNs), and the features incorporated in Stage 3. Hanaoka (2007) coded PFNs and FNs into four categories: lexis, grammar, content, and other.

This study, in response to the data collected, classified them into five categories: lexis, spelling, grammar, ideas and their expression, and other. Like in Hanaoka's (2007) study, the identification of lexical and grammar features followed Williams's (2001) classification of Language Related Episodes (LREs): "The lexical category essentially includes anything that would fit into the categories "What does this mean?" "How do you say this?" or "Which word should I use here?” In contrast, the grammar/morphology/syntax category includes LREs that revolve around tense choices, grammatical morphology, word order, and other features generally considered part of grammar” (pp. 330-331).

The spelling category included those aspects that would fit into the question "how do you spell this?”. Following Cumming (1990), the ideas as well as the means to express those ideas that students noticed and/or incorporated in their texts were included in the "ideas and expression" category, and, finally, the "other" category was intended to cover those features which were difficult to code.

The following examples illustrate the way in which the Stage 1 PFNs and Stage 2 FNs were coded into the five categories.

\section{Lexis}

“I don’t know how to say ‘pareja' in English.” (Stage 1 PFN)

"I wouldn’t say “checking”, as model A does; I'd rather say “find”” (Stage 2 FN)

In the first example, the student is looking for an English lexical item for a Spanish word but he does not know how to translate it. In the second example, the student evaluates the appropriacy or truth value of two lexical choices. 


\section{Spelling}

"I don't know if "loking” has to be written with two 'oo'” (Stage 1 PFN)

"I didn’t know if “looking” is with two “oo” and I realized it is. (Stage 2 FN)

In the first example, the student does not know how to spell a word. In the second, the student realizes how to write such a word.

3. Grammar

"We don't know how to use the conditional tense of want." (Stage 1 PFN)

"We didn’t know how to say "no les gustaba” and we wrote "I don’t like them”, but now we like the way it is expressed in model B "They were very shocked and disappointed””. (Stage 2 FN)

In the first example, two students writing in collaboration do not know how to form the conditional tense. In the second example, the students do not know how to say something grammatically, but they realize they can express it in a different way.

\section{Ideas and expression}

No examples of this category were found in Stage 1.

"We would have used the first sentence of model A.” (Stage 2 FN)

In this example, the students seem to like an idea and the way it is expressed in one of the models. They would have used something like that instead of the sentence they really wrote.

5. Other

No examples of this category were found in Stage 1.

"I didn't find anything interesting in the models." (Stage 2 FN)

"I was impressed by model A's interpretation of the pictures." (Stage 2 FN).

In these notes, neither student refers to any specific aspect of their texts. As it turned out to be quite difficult for us to include this kind of notes in any of the previous categories, we followed Hanaoka (2007) and decided to add the "other” category to our coding scheme.

The incorporation of features was operationalized as any attempt by the students to include in the revised text (Stage 3) any aspect noticed in stages 1 and/or 2 even if it contained minor errors.

\section{RESULTS}

Research Question 1: What aspect of language do L2 learners notice while writing their original composition individually and in pairs? (Nature of Stage 1 noticing)

The frequencies, means and proportions of the problematic features noticed (PFNs) by the learners while writing their original composition are shown in Table 1. Learners noted a total 
of 32 PFNs, that is, an average of 2.63 per participant. These PFNs were mostly of a lexical nature, although the percentage here (84.37\%) is slightly lower than in Hanaoka's (2007) study, which reported that about $92.4 \%$ of the PFNs noticed by learners were also lexically oriented.

In our case, 19 out of the 32 PFNs were noted by individuals (an average of 3.8 features per participant) while the remaining 13 were noted by pairs (an average of 2.16 features per pair). It may then be observed that participants working alone were more likely to notice "holes" in their linguistic resources, when writing a picture-based story, than participants working in pairs.

\begin{tabular}{|c|c|c|c|c|c|c|c|c|c|c|c|c|}
\cline { 2 - 13 } & \multicolumn{4}{|c}{ All participants (11) } & \multicolumn{3}{c|}{ Individuals (5) } & \multicolumn{4}{c|}{ Pairs (6) } \\
\cline { 2 - 13 } & $\mathbf{n}$ & $\mathbf{0}$ & mean & $\mathbf{s . d}$ & $\mathbf{n}$ & $\mathbf{\%}$ & mean & s.d & $\mathbf{n}$ & \% & mean & s.d \\
\hline Lexis & 27 & 84.37 & 2.45 & 1.57 & 16 & 84.21 & 3.2 & 1.64 & 11 & 84.62 & 1.83 & 1.32 \\
\hline Spelling & 2 & 6.25 & 0.18 & 0.40 & 2 & 10.53 & 0.4 & 0.54 & 0 & 0 & 0 & 0 \\
\hline Grammar & 3 & 9.375 & 0.27 & 0.64 & 1 & 5.26 & 0.2 & 0.44 & 2 & 15.38 & 0.33 & 0.81 \\
\hline $\begin{array}{c}\text { Ideas \& } \\
\text { expression }\end{array}$ & 0 & 0 & 0 & 0 & 0 & 0 & 0 & 0 & 0 & 0 & 0 & 0 \\
\hline Other & 0 & 0 & 0 & 0 & 0 & 0 & 0 & 0 & 0 & 0 & 0 & 0 \\
\hline Total & $\mathbf{3 2}$ & $\mathbf{1 0 0}$ & $\mathbf{2 . 6 3}$ & $\mathbf{1 . 4 4}$ & $\mathbf{1 9}$ & $\mathbf{1 0 0}$ & $\mathbf{3 . 8}$ & $\mathbf{1 . 4 5}$ & $\mathbf{1 3}$ & $\mathbf{1 0 0}$ & $\mathbf{2 . 1 6}$ & $\mathbf{0 . 9 7}$ \\
\hline
\end{tabular}

Table 1. Frequencies, proportions and means of problematic features noticed (PFNs) in the Stage 1 writing task

This different degree of attention to "holes" by each group is corroborated when we look at the time participants needed to write their original texts (see Table 2). The data indicate that individuals needed an average of 18 minutes to write an average of 37,8 words, while the learners working in pairs needed less time (an average of 13 minutes) to write longer texts (an average of 46 words per participant). Besides, the larger standard deviation for individuals suggests greater variation between individually composed texts.

\begin{tabular}{|c|c|c|c|c|}
\cline { 2 - 5 } \multicolumn{1}{c|}{} & \multicolumn{2}{c|}{ Time on task (in minutes) } & \multicolumn{2}{c|}{ Number of words } \\
\cline { 2 - 5 } \multicolumn{1}{c|}{} & Mean & SD & Mean & SD \\
\hline Individuals & 18 & 2.12 & 37,8 & 14,33 \\
\hline Pairs & 13 & 3.18 & 46 & 6,19 \\
\hline
\end{tabular}

Table 2. Time on task and number of words written per group (Stage 1)

\section{Research Question 2: What do individual students and pairs notice as they compare their original text to native-speaker models of writing? (Nature of Stage 2 noticing)}

The frequencies, means and proportions of the features noticed (FNs) by the learners in the Stage 2 comparison task are shown in Table 3. 


\begin{tabular}{|c|c|c|c|c|c|c|c|c|c|c|c|c|}
\hline & \multicolumn{4}{|c|}{ All participants (11) } & \multicolumn{4}{|c|}{ Individuals (5) } & \multicolumn{4}{|c|}{ Pairs (6) } \\
\hline & $\mathbf{n}$ & $\%$ & mean & s.d & $\mathbf{n}$ & $\%$ & mean & s.d & $\mathbf{n}$ & $\%$ & mean & s.d \\
\hline & 5 & 20.83 & 0.45 & 0.68 & 2 & 22.22 & 0.4 & 0.89 & 3 & 20 & 0.5 & 0.54 \\
\hline & 1 & 4.17 & 0.1 & 0.30 & 1 & 11.12 & 0.2 & 0.44 & 0 & 0 & 0 & 0 \\
\hline & 1 & 4.17 & 0.1 & 0.30 & 0 & 0 & 0 & 0 & 1 & 6.7 & 1.17 & 0.40 \\
\hline & 13 & 54.16 & 1.18 & 1.13 & 4 & 44.44 & 0.8 & 1.09 & 9 & 60 & 1.5 & 1.21 \\
\hline & 4 & 16.67 & 0.36 & 0.50 & 2 & 22.23 & 0.4 & 0.44 & 2 & 13.3 & 0.33 & 0.51 \\
\hline Total & 24 & 100 & 2.2 & 0.63 & 9 & 100 & 1.8 & 0.69 & 15 & 100 & 3.5 & 0.77 \\
\hline
\end{tabular}

Table 3. Frequencies, proportions and means of features noticed (FNs) in the Stage 2 comparison task.

Learners noted a total of 24 FNs (an average of 2.2 features per participant), 9 of which were noticed by individuals (an average of 1.8 features per participant) and 15 by pairs (an average of 3.5 per pair). Thus, the total number of features noticed was lower in Stage 2 than Stage 1 both across groups (Stage 2, $\mathrm{n}=24$; Stage 1, $\mathrm{n}=32$ ) and for the individual group (Stage 2, $n=9$; Stage $1, n=19$ ), while the pair group noted a similar number of features when writing their original texts and when comparing their texts to the models provided (Stage 1=13; Stage $2=15)$.

The most notable difference, however, between both stages was that, across groups, most FNs in Stage 2 had to do with ideas and their expression ( $n=13 ; 54.16 \%$ of the total), with lexical FNs only accounting for 5 FNs (20. 83\% of the total). The increase in the former may be linked to the fact that some students noted that some of the expressions used in the models differed from their own and could be used to improve their original texts. For instance, a participant said that he would change the beginning of his story for the one written in model B, as he considered the latter to be clearer and easier to read. The remaining episodes of noticing included $1 \mathrm{FN}$ related to grammar, $1 \mathrm{FN}$ to spelling and 4 coded as "other".

Table 4 shows the relationship of the 24 FNs to the Stage 1 PFNs. As can be seen, only 3 Stage 2 FNs were related to Stage 1 PFNs. One of the features related was noticed by individuals while the other 2 were noticed by pairs. These FNs involved intended words that the participants had not been able to use or access through alternative forms, such as 'waiter' or 'couple', and a word that an individual did not know how to spell (“looking”).

\begin{tabular}{|c|c|c|c|c|c|c|}
\cline { 2 - 7 } & \multicolumn{2}{|c|}{ All participants (11) } & \multicolumn{2}{c|}{ Individuals (5) } & \multicolumn{2}{c|}{ Pairs (6) } \\
\cline { 2 - 7 } & $\mathbf{n}$ & mean & $\mathbf{N}$ & mean & n & mean \\
\cline { 2 - 7 } & 3 & 0.27 & 1 & 0.2 & 2 & 0.33 \\
\hline Total & $\mathbf{2 4}$ & $\mathbf{2 . 1 7}$ & $\mathbf{9}$ & $\mathbf{1 . 8}$ & $\mathbf{1 5}$ & 2.17 \\
\hline
\end{tabular}

Table 4. Stage 2 FNs by relation to Stage 1 PFNs. 
On the other hand, the 21 FNs that were not related to Stage 1 PFNs included, above all, ideas and ways of expressing them (the "ideas and expression" category) that students had not even imagined in their first composition, and words that had not been consciously searched for during the original writing stage. Of these unrelated 21 FNs, 8 were noticed by individuals and 13 by pairs.

In contrast with the Stage 1 task, the time both groups needed to develop the Stage 2 task was very similar. As shown in Table 5, learners working in pairs needed an average of 9.6 minutes to compare their original texts to the native-speaker models, while learners working individually needed about 10.5 minutes to complete the same task.

\begin{tabular}{|c|c|c|}
\cline { 2 - 3 } \multicolumn{1}{c|}{} & \multicolumn{2}{c|}{ Time on task (in minutes) } \\
\cline { 2 - 3 } \multicolumn{1}{c|}{} & Range & Mean \\
\hline Individuals (5) & $9-12$ & 10.5 \\
\hline Pairs (6) & $9-10$ & 9.6 \\
\hline
\end{tabular}

Table 5. Time on task (Stage 2)

\section{Research Question 3: What are the effects of stage 1 and stage 2 noticing of the subsequent revision? (Stage 3)}

Before presenting these findings, it is important to point out that, following Hanaoka (2007), the problematic features that the participants noticed while composing their original narrative (PFNs) were classified as either "solvable" or "unsolvable" from the two native speaker models presented to them later. A "solvable” PFN referred to a problematic feature for which either model A or model B, or both, provided at least one solution. For example, in the present study, some participants did not know how to say "camarero". Model A provided the solution "waiter". Therefore, PFNs involving the Spanish "camarero" were considered "solvable”. On the other hand, an "unsolvable" PFN referred to a problematic feature for which the models did not provide a solution. For example, a participant noted that she was not sure whether after "couldn't" the verb should be put in the present tense or in the past tense. Neither model A nor model B provided any solution to this problematic feature because neither of them made any reference to this grammatical point. Therefore, this problem was considered "unsolvable".

The participants in this study produced a total of 32 PFNs in the "lexis”, "grammar" and "spelling” categories, of which 14 PFNs (43,75\%) were solvable, and 18 (56.25\%) were unsolvable. During the Stage 1 writing task, participants had solved on their own 7 (50\%) of solvable PFNs by using the same features that were included in the models to be presented later. Therefore, these features were excluded from the analysis. The remaining 7 PFNs, 4 for individuals and 3 for pairs, were then analyzed in order to examine the frequencies with which the participants noticed solutions to these PFNs in the Stage 2 comparison task and the frequencies with which they incorporated those solutions in their subsequent revisions. 


\begin{tabular}{|l|c|c|c|c|c|c|c|c|c|}
\cline { 2 - 10 } \multicolumn{1}{l|}{} & \multicolumn{3}{|c|}{$\begin{array}{c}\text { All participants } \\
\text { (11) }\end{array}$} & \multicolumn{2}{c|}{ Individuals (5) } & \multicolumn{3}{c|}{ Pairs (6) } \\
\cline { 2 - 11 } & $\mathbf{n}$ & mean & SD & n & mean & SD & n & mean & SD \\
\hline Solvable PFNs & 7 & 0.64 & 0.50 & 4 & 0.8 & 0.44 & 3 & 0.5 & 0.54 \\
\hline Stage 2 noticing & 3 & 0.27 & 0.50 & 1 & 0.2 & 0.44 & 2 & 0.33 & 0.54 \\
\hline $\begin{array}{l}\text { Stage } 3 \text { incorporations related to the solvable } \\
\text { PFNs }\end{array}$ & 2 & 0.18 & 0.40 & 1 & 0.2 & 0.44 & 1 & 0.17 & 0.40 \\
\hline Stage 3 incorporations related to the FNs & 11 & 1.18 & 1.13 & 2 & 0.6 & 0.89 & 9 & 1.67 & 1.22 \\
\hline $\begin{array}{l}\text { Stage } 3 \text { incorporations related neither to Stage } \\
1\end{array}$ & 3 & 0.72 & 0.64 & 0 & 0 & 0 & 3 & 0.5 & 0.83 \\
\hline $\begin{array}{l}\text { Stage } 3 \text { incorporations that did not appear in } \\
\text { the models }\end{array}$ & 1 & 0.09 & 0.30 & 1 & 0.2 & 0.44 & 0 & 0 & 0 \\
\hline
\end{tabular}

Table 6. Incorporations to subsequent revisions (Stage 3).

Table 6 shows that only 3 of those 7 solvable PFNs were noticed by learners in the models provided (Stage 2), 1 of them being noted by an individual and the remaining 2 by pairs. Finally, only 2 of those 3 features were incorporated into the revision task (Stage 3) that was carried out three days later. Of these 2 features (related to lexis and spelling respectively), one was incorporated by an individual and the other by a pair.

In addition to the features mentioned above, which were related to the combination of Stages 1 and 2, other features only noted in Stage 2 were also incorporated into the revision task. These features were largely related to the content of the story and the way to express it $(n=7)$ and, secondarily, to lexical concerns $(n=4)$. As shown in the Table, 2 of those 11 features were incorporated by individuals, and the remaining 9 by pairs.

Table 6 also shows that the learners incorporated 3 features which were related neither to Stage 1 nor to Stage 2. However, these features appeared in the models and they can therefore be considered as "covert" (Hanaoka, 2007). All of them were incorporated by pairs and reflected lexical concerns. Finally, it should be noted that one of the features incorporated into the revision was not in the models (see the bottom row in Table 6). An individual noticed in the Stage 1 task that she did not know how to say 'personas' and she wrote 'persons'. However, in Stage 3 she wrote "people", a feature that did not appear either in model A or in model B.

Finally, we can observe in Table 7 that individual participants needed an average of 13.2 minutes to complete the task while pairs needed 2 minutes less. However, the latter ended up writing longer texts (an average of 56.8 words per participant) than the former (an average of 
39.4 words). As in the case of the texts written in Stage 1, the larger standard deviation for individuals suggests greater variation among individually composed texts.

\begin{tabular}{|c|c|c|c|c|}
\cline { 2 - 5 } \multicolumn{1}{c|}{} & \multicolumn{2}{c|}{ Time on task (in minutes) } & \multicolumn{2}{c|}{ Number of words } \\
\cline { 2 - 5 } \multicolumn{1}{c|}{} & Mean & SD & Mean & SD \\
\hline Individuals (5) & 13.2 & 3.03 & 39.4 & 18.45 \\
\hline Pairs (6) & 11.3 & 2.78 & 56.8 & 9.37 \\
\hline
\end{tabular}

Table 7 Time on task and number of words written per group (Stage 3)

\section{DISCUSSION}

The present study was set up to investigate noticing as related to composing and subsequent processing of feedback in the context of individual and collaborative writing. In what follows the main sets of findings that emerged from the data will be discussed with respect to previous cognitively-oriented research on written feedback.

\subsection{Learner noticing in the composing and comparison stages}

Our data showed that learners, while writing their original compositions both individually and in pairs, noticed mainly lexical problems. These problems were generally formulated in terms of lack of knowledge (e.g., “no sé decir “escogieron””; “no sé decir “llamado” y “entonces” y he puesto una línea”; “¿cómo se dice lo esperado?”; “no sabemos cómo se dice “desde entonces” y lo hemos dejado en blanco") ${ }^{1}$, or, alternatively, in the form of proposals for potential solutions (e.g., "no estamos seguros de cómo se dice "buscaron”, vamos a poner searched”; "no estoy segura de cómo se dice "cuando” sin preguntar, he puesto "when”; "no sé como se dice ‘no tenían', hemos puesto 'haven’t' pero no estamos seguros si es correcto”) 2 . It may be concluded, then, that the secondary-school students in our study noticed lexical "holes" (Swain, 1998) in their interlanguage through output, a finding that fully confirms the data reported by Hanaoka for the Stage 1 task in her 2006 and 2007 studies with Japanese university students.

This spontaneous priorization of lexical concerns before the writers received the feedback treatment should come as no surprise, since research has shown that (i) lexical access and retrieval is pervasive in all subprocesses of L2 writing (see Manchón, Murphy \& Roca de Larios, 2007); (ii) learners tend to allocate more attentional resources to lexis than to other linguistic aspects when addressing open-ended tasks of the sort used in this study (Manchón, in press b); and that (iii) attention to lexical elements predominates in the completion of free activities when the focus on form is initiated by the learners themselves (Ellis, 2001; Swain \& Lapkin, 1995; Williams, 2001). 
When individuals and pairs compared their original texts to native-speaker models, both groups predominantly noticed features related to ideas and their expression. These concerns were formulated in a variety of ways that included the students' acknowledgement of the ideas and expressions used in the models (e.g., "nos ha gustado la expresión "one day one young couple”"; "nos ha gustado la frase "overlooking the ocean””; "me gusta la última frase del modelo B”; “me ha gustado el desarrollo y el final del modelo A, ya que es más desarrollado que el mío") $)^{3}$, their intention of having used some of those ideas and expressions in their original texts if they had had the chance ("me hubiera gustado poner "we could get a good view of the sea' del modelo B”; "la última frase la hubiésemos puesto como en el modelo A"; "en vez de poner el principio que hemos puesto, nos hubiera gustado poner la $1^{\text {a }}$ frase del modelo $\left.\mathrm{A}^{\prime}\right)^{4}$, or their perceptions of the differences between their own ideas and those conveyed in the models ("la $4^{\mathrm{a}}$ frase del modelo A está bien, pero hemos puesto que el restaurante estaba lleno"; "nos ha gustado la última frase del modelo B, pero hemos puesto que se fueron al McDonalds y después a casa”; "nosotros creíamos que no había mesas, pero el camarero les dijo que se podían sentar en la mesa de la esquina”) ${ }^{5}$. The increase in Stage 2 of concerns related to ideas and their expression corroborates a similar, though not so prominent, trend previously reported by Hanaoka (2007), as his participants were also found to increase their noticing of content features (similar to our "ideas and expression” category) from practically none in Stage 1 to $30 \%$ of all FNs in Stage 2. This shows a useful role of native-speaker models in promoting learner noticing and specifically in drawing learners' attention to the ideas and expressions they write in their original texts.

However, the fact that the dominant concerns of our participants in Stage 1 and Stage 2 were so different is not in keeping with the findings reported in previous studies that have used models (Hanaoka, 2007) or reformulations (Qi \& Lapkin, 2001) as feedback techniques. These studies report that their participants noticed and searched for solutions in the feedback provided for about two-thirds of the solvable "holes" they had previously noticed when writing their original texts in Stage 1 . However, that was not the case with our participants. In spite of the small number of solvable PFNs ( $n=7)$ in Stage 1, their FNs in Stage 2 showed that only 3 of those PFNs (around 43\%) were noted by the students, as their attention was mainly focused on the ideas and expressions in the models that now appealed to them. Therefore, the sense of lack of fulfillment that the participants in those studies had experienced as they noticed "holes" while writing their texts, and which had pushed them to search for satisfactory solutions in the reformulated texts or models, was not so apparent among the participants in our study.

In addition to the fact that only a few PFNs were solvable through the models (see explanation in the next section), several arguments can be adduced to account for these differences across stages. For one thing, probably as a result of their low level of developmental readiness to notice the feedback provided (Truscott, 1996), the students' attention may have been directed and controlled by the perceptual saliency (Hanaoka, 2006; 
Sachs \& Polio, 2007) or focus effect (Broekkamp \& van der Bergh, 1996) of the elements involved in each stage of the writing task, i.e., pictures in Stage 1 (the participants did not know many words to express what they saw and, consequently, they had to focus their attention on lexical items), and models in Stage 2 (the participants, after their previous attempt to write the story, were especially receptive to the ideas and expressions that now became salient in the models). Besides, the guided noticing implemented in the present research in the form of directions given to the participants to complete the task may have also increased the proportion of PFNs related to lexical concerns and FNs related to ideas and their expression. However, despite the purported importance of these variables, further research is required before it can be convincingly demostrated that saliency and guided noticing are key factors in written feedback processing (Sachs \& Polio, 2007; Santos, López Serrano \& Manchón, 2010).

\subsection{From noticing to subsequent revisions}

As for the effects of noticing in Stages 1 and 2 on subsequent revisions in Stage 3, our data showed that the participants, out of a total of 32 PFNs in Stage 1, noticed only 7 problems (around 22\%) that we regarded as solvable from the models. As mentioned above, only 3 of these 7 problems were noticed in Stage 2, but only 2 of those 3 were later incorporated in the subsequent revision stage.

The low percentage of PFNs regarded as solvable in our study is in stark contrast with the high percentage of solvable PNFs (over 60\%) reported by Hanoka (2007). This finding seems to suggest that either our participants made a very idiosyncratic interpretation of the story cued in the pictures or else that the way the story was rendered in the models differed substantially from the way it was developed in the texts written by the students. The first interpretation may be discarded, partially at least, since a cursory analysis of the texts produced in the writing-only stage reveals that, to a greater or lesser extent, all of them captured the essentials of the narrative. The second interpretation, in contrast, seems to be more in line with the characteristics of both text types. The ideational and linguistic distance between the written texts and the models was so wide that the students could hardly rely on the latter to solve the "holes" previously detected in the writing-only stage. Consequently, the most practical alternative at their disposal seemed to be the use of those models as source texts for borrowing purposes (Plakans, 2009; Shi, 2004).

In fact, an analysis of the notes taken in the comparison stage shows that, with the exception of a few occasions on which the focus of attention was on the meaning of individual words, the models were often "mined" (see the literature on integrated writing tasks, e.g., Hirvela, 2004; Plakans, 2009) to single out the ideas and expressions that suited the students' purposes. As shown in the examples cited in the previous section, the chunks selected were often beyond the word level, ranged from phrases to sentences and were generally justified by the students on the grounds of simple intuitions or a sense of what might be suitable for their 
own texts ("me gusta”, “cambiaríamos”, etc.). This form of accounting for their choices seems to suggest that the level of awareness experienced by these students was basically simple or perfunctory rather than elaborate or substantive (Kuikken \& Vedder, 2002; Qi \& Lapkin, 2001), and that, as a result, their noticing of gaps was taking place at the level of "detection” rather than "understading" (Robinson, 1995; Schmidt, 2001; Tomlin \& Villa, 1994). However, in spite of this level of awareness, they managed to incorporate more than half of the ideas and expressions drawn from the models into their revisions three days later (Stage 3). As the models had been removed, this means that some attempts at memorizing the new chunks must have been in operation in Stage 2, a finding which has also been reported in previous studies (Hanaoka, 2007; Sachs \& Polio, 2007).

On the other hand, around 50\% of all FNs noticed in Stage 2 -including features related to lexis $(n=5)$, spelling $(n=1)$, and ideas and expression $(n=7)-$, were incorporated into the revisions, and if we compare this figure with those reported in other studies, interesting similarities and differences emerge. Our percentage is fairly similar to the $60 \%$ of incorporations reported by Adams (2003), but very low compared to the $78 \%$ or more reported by Swain \& Lapkin (2002). Following Adams (2003), a reason to account for these differences might be that our students came from an instructional context in which grammar and vocabulary instruction was quite explicit, while the French immersion students in Swain \& Lapkin's study were probably more used to learning in the implicit conditions demanded by the type of feedback provided (reformulation, in their case, or modelling, in our case). If this explanation were confirmed by further research, it might be tentatively concluded that contextual factors other than the task itself may play a role in learners' noticing and incorporation of feedback.

In addition to the features already mentioned, the participants also incorporated a reduced number of lexical features $(n=3)$ which, despite appearing in the models, had not been reported in the comparison stage. This shows that, in spite of its important advantages, notetaking is physically demanding and time-consuming as a self-report technique (Hanaoka, 2007), and shares with many other introspective methods the problem of incomplete coverage of what learners notice (Jourdenais, 2001).

\subsection{Individual and collaborative approaches to feedback}

A further area of concern in the present study was related to the way individuals and pairs addressed the different stages involved in the use of modelling as a feedback technique. As shown in the previous section on findings, the data indicated that, when writing their stories, individuals noticed more lexical holes in their interlanguage than pairs (Stage 1). A possible explanation for this finding may lie in the fact that pairs, as a result of the exchange of linguistic knowledge involved in this condition, could have had more linguistic resources at their disposal than individuals and, consequently, noticed fewer holes. In any case, this is only 
speculation that will have to be confirmed by further studies comparing, for example, the protocols of individual writers thinking aloud with the recordings of learners engaged in collaborative writing and including, if possible, stimulated recall methods (see Kim, 2008).

In contrast, when it came to the task of comparing their texts with the models, the pattern was exactly the opposite. The participants working individually noticed fewer features than in the previous stage, while the pairs noticed more. If we bear in mind that most features noticed in this Stage 2 were related to the ideational content of the story as well as to different ways of expressing it, we must conclude that the collaborative condition seems to be especially suited to allowing learners, at least of this age and at this proficiency level, to detect chunks in the models that may later be used to improve both the ideas and the means of expression in their own stories.

These findings add a further dimension to the reported superiority of collaborative over individual writing in such areas as the accuracy of the texts produced (Storch \& Wigglesworth, 2007; Wigglesworth \& Storch, 2009), the deeper processing of new words (Kim, 2008), the uptake of word order related to negative adverbs (Reinders, (2009) and the purported quality of the attentional processes activated (see López Serrano, 2010). They also confirm previous tenets about the positive effects of collaborative writing on noticing (Storch, 2008; Swain \& Lapkin, 2002) and provide further support for reported findings about the superiority of the combination of the speaking and writing modes involved in collaboration over the oral production mode alone when it comes to promoting focus on form (Niu, 2009).

Finally, the participants in our study working in collaboration were found to write longer texts in Stages 1 and 3 and in a shorter period of time than individuals. This finding runs counter to reports from previous studies in which collaborative writers have generally been found to take longer than individual writers to write shorter texts or texts of a similar length (e.g., Storch, 1999, 2005). Although our data do not allow us to know what kind of interaction patterns were taking place between the different dyad members, it may tentatively be speculated that their higher level of productivity was the outcome of their collaboration in the decision-making processes posed by the tasks (see Swain, 2000; Watanable \& Swain, 2007). Maybe their degree of involvement and congeniality (see the Method section), coupled with the task demands, exempted them from spending valuable task time on reaching an agreement on, for example, how the work should be organized, who should be the scribe or what type of meaning should be conveyed (Malmqvist, 2005). In any case, the analysis of time on task in relation to the degree of focus on form afforded by individual and collaborative writing is a crucial issue to be addressed in future research for both theoretical and pedagogical reasons (Manchón, in press b). 


\section{CONCLUSIONS}

The findings of the present study, which was intended as an attempt to apply modelling feedback techniques in the secondary school context, show the importance of the noticing function of output. While writing a narrative, the participants, in spite of their age and L2 proficiency level and regardless of whether they worked individually or in pairs, noticed their linguistic needs (holes), most of which were lexical in nature, and autonomously searched for solutions in the models provided. Although very few solutions were found and even fewer were incorporated into subsequent revisions, the participants, while comparing their narratives to the two native-speaker models, noticed their gaps, selected ideas and ways to express those ideas on the content of the pictures, and incorporated a reasonable number of them into subsequent revisions. Since the learners working in pairs were found to notice and incorporate more features than learners working individually, it may tentatively be concluded that working in collaboration has positive effects on helping learners identify from models the linguistic features they need and in facilitating subsequent retention of those features.

If we intend to generalize the application of these feedback techniques to the teaching of L2 writing, a number of pedagogical recommendations could be suggested. First of all, we must make sure that the models are in consonance with the students' conception of the task and their level of L2 proficiency. Although our students' interpretations of the picture prompts were generally in line with the ones portrayed in the models, their elaboration differed greatly in the number of details and expressions used, and this distance did not allow them to benefit from the models as much as they could have. If learners are to make the most of nativespeaker models for feedback purposes, the perceived difficulty of the texts presented to the students should previously be assessed. In addition, we must be careful with the instructions given to learners for reporting what they notice. In our case, the participants' low proficiency level probably led some of them to follow the wording of the prompts provided too literally and, as a result, many of the features they noted seemed to be a clear reflection of that type of guidance. Finally, in many foreign language contexts like the one reported in the present study official curriculum guidelines do not give teachers any recommendations as to how to provide feedback to their students. This lack of guidance and the educational context in which they teach often leads them to rely on traditional forms of feedback solely based on their intuitions and practical knowledge. As an alternative to this state of affairs, teachers should be trained in techniques like the ones tested in this study so that they may enlarge their repertoire of feedback options and make use of those which, within each particular context, are more likely to help students notice gaps between their interlanguage and the target language. 


\section{LIMITATIONS AND SUGGESTIONS FOR FUTURE RESEARCH}

Because of being exploratory in nature, the present study has some important limitations. First, given the small number of participants involved, the results reported above should be considered only as tentative answers to our research questions. Second, the data collection procedure used in the study, i.e., note-taking, may have amplified the positive effects of output production by giving participants the opportunity to reprocess and improve their retention of the noticed features. Further studies should be conducted in which other techniques to capture noticing such as thinking-alouds and interaction recordings are used to compare results. These techniques, if used with the appropriate coding system (e.g., Leow, 1997), seem to hold promise for providing insights into learners' awareness of linguistic forms and subsequent use of them (Sachs \& Polio, 2007). Third, attention should be paid to text productivity in relation to the grouping of learners. Our data showed that pairs, while generally speding less time than individuals on the completion of the different parts of the task, ended up writing longer texts. Further research should analyze more rigorously whether learners working in collaboration are in a better position than individuals to come up with more ideas, pool their linguistic knowledge, resolve their doubts more quickly and, eventually, have more time available to repair their texts (Storch, 2007). Fourth, the feedback provided was not equally effective for all the participants, as shown by the relatively large standard deviations reported in the length of the texts produced in Stage 3, especially by individual writers. In consonance with these data, a promising line of inquiry in the field of invidual differences would involve the analysis of how learners' goals, attitudes and beliefs influence their willingness to deal with different types of feedback (Storch \& Willingsworth, 2010) and how these factors change as a function of the novelty of the linguistic items involved (Sachs \& Polio, 2007). Finally, the present study involved a one-shot feedback treatment. Therefore, the results presented can legitimately be viewed only as evidence of learners' uptake rather than acquisition (Reinders, 2009). Future studies should make use of longitudinal designs to investigate the long-term effects of modelling as a feedback technique on L2 learning, an issue of great theoretical and practical relevance in the intersection of L2 writing studies and SLA studies of feedback on writing.

\section{ACKNOWLEDGEMENTS}

This study is part of a research project supported by a research grant from the Fundación Séneca, Murcia Regional Government Agency for Science and Technology (Research Grant 11942/PHCS/09). 


\section{NOTES}

${ }^{1}$ I don't know how to say “chose”; I don't know how to say "called” and "then” and I've just drawn a line; how do you say "what they expected”?; we don't know how to say "ever since” and we've left a blank space.

${ }^{2}$ We are not sure how to say "looked for" and we're going to write "searched"; I'm not sure how to say “when” when you're not asking, and I've put “when”; I don't know how to say “they had not” and we've put "haven't", but we're not sure whether this is correct.

${ }^{3}$ We like the expression "one day one young couple”; we like the expression “overlooking the ocean”; I like the last sentence in model B; I like the way the story develops and ends in model A, as it is more elaborate than mine.

${ }^{4}$ I would've put "we could get a good view of the sea” from model B; we would've written our last sentence as it is written in model A; we would've put the first sentence in model A as the opening of our story.

${ }^{5}$ The fourth sentence in model A is OK, but we've written that the restaurant was full; we like the last sentence in model B, but we've written that they went to McDonald's and then back home; we thought that all the tables were taken, but the waiter told them that there was a free table in a corner.

\section{REFERENCES}

Adams, R. (2003). L2 output, reformulation and noticing: implications for IL development. Language Teaching Research, 7, 347-376.

Batstone, R. (1996). Noticing. ELT Journal, 50, 273.

Broekkamp, H. \& van den Bergh, H. (1996). Attention strategies in revising an L2-text. In, G. Rijlaarsdam, H. van den Bergh \& M. Couzijn (Eds.), Theories, models and methodology in writing research (pp. 169-181). Amsterdam: AUP.

Cohen, A. D. \& Cavalcanti, M. C. (1990). Feedback on compositions: Teacher and student verbal reports. In B. Kroll, (Ed.), Second language writing: Research insights for the classroom (pp. 155-177). Cambridge: Cambridge University Press.

Conrad, S. M. \& Goldstein, L. M. (1999). ESL student revision after teacher-written comments: Text, contexts and individuals. Journal of Second Language Writing, 8, 147-179.

Cumming, A. (1990). Metalinguistic and ideational thinking in second language composing. Written Communication, 7, 482-511.

de Bot, K. (1996). The Psycholinguistics of the Output Hypothesis. Language Learning, 46, 529-555.

Ellis, N. (2005). At the interface: Dynamic interactions of explicit and implicit languag knowledge. Studies in Second Language Acquisition, 27, 305-352.

Ellis, R. (1995). Interpretation tasks for grammar teaching. TESOL Quartely 29, 87-105.

Ellis, R. (2001). Introduction: investigating form-focused instruction. Language Learning, 51 (Suppl. 1), 1-46.

Ellis, R., Sheen, Y. Murakami, M. \& Takashima, H. (2008). The effects of focused and unfocused written corrective feedback in an English as a foreign language context. System, 36, 353-371.

Ferris, D. (2004). The "grammar correction" debate in L2 writing: Where are we and where do we go from here? (and what do we do in the meantime...?). Journal of Second Language Writing, 13, 49-62.

Ferris, D. (2010). Second language writing research and written corrective feedback in SLA. Studies in Second Language Acquisition, 32, 181-201. 
Gutiérrez, X. (2008). What Does Metalinguistic Activity in Learners' Interaction During a Collaborative L2 Writing Task Look Like? The Modern Language Journal, 92, 519-537.

Hanaoka, O. (2006). Noticing from models and reformulations: A case study of two Japanese EFL Learners. Sophia Linguistics, 54 , 167-192.

Hanaoka, O. (2007). Output, noticing, and learning: An investigation into the role of spontaneous attention to form in a four-stage writing task. Language Teaching Research, 11, 459-479.

Hedgcock, J. \& Lefkowitz, N. (1994). Feedback on feedback: Assessing learner receptivity to teacher response in L2 composing. Journal of Second Language Writing, 1, 255-276.

Hirvela, A. (2004). Connecting reading and writing in second language writing instruction. Ann arbor, MI: The Univerity of Michigan Press.

Hyland, F. (1998). The impact of teacher written feedback on individual writers. Journal of Second Language Writing, 7, 255- 286.

Hyland, F., \& Hyland, K. (2001). Sugaring the pill: Praise and criticism in written feedback. Journal of Second Language Writing, 10, 185-212.

Izumi, S. (2003). Comprehension and production processes in second language learning: In search of the psycholinguistic rationale of the Output Hypothesis. Applied Linguistics, 24, 168-196.

Johnson, K. (1988). Mistake correction. ELT Journal, 42, 89-96.

Jourdenais, R. (2001). Cognition, instruction and protocol analysis. In P. Robinson, (Ed.), Cognition and Second Language Instruction (pp. 354-375). Cambridge: Cambridge University Press.

Kim, Y. (2008). The contribution collaborative and individual tasks to the acquisition of L2 vocabulary. The Modern Language Journal, 92, 114-130.

Kuiken, F., \& Vedder, I. (2002). Collaborative writing in L2: The effect of group interaction on text quality. In S. Ransdell \& M. Barbier (Eds.), New Directions for Research in L2 Writing (pp. 169-188). Dordrecht: Kluwer.

Lapkin, S., Swain, M. \& Smith, M. (2002). Reformulation and the learning of French pronominal verbs in a Canadian French immersion context. The Modern Language Journal, 86, 485-507.

Lázaro Ibarrola, A. (2009). Reformulation and self-correction: testing the validity of correction strategies in the classroom. RESLA, 22, 189-215.

Lee, I. (2004). Error correction in L2 secondary writing classrooms: The case of Hong Kong. Journal of Second Language Writing, 13, 285-312.

Leki, I. (1991). The preference of ESL students for error correction in college-level writing classes. Foreign Language Annals, 24, 203-218.

Leow, R. (1997). Attention, awareness, and foreign language behavior. Language Learning, 47, 467505.

López Serrano, S. (2010). A review of individual vs. collaborative writing. Unpublished manuscript. Universidad de Murcia.

Lowen, S. and Philp, J. (2006). Recast in the adult English L2 classroom: characteristics, explicitness and effectiveness. The Modern Language Journal, 90, 536-556.

Malmqvist, A. (2009). How does group discussion in reconstruction tasks affect written language output? Language Awareness, 14, 128-141.

Manchón, R. (2009). Writing in foreign language contexts. Learning, teaching and research. Clevendon: Multiligual Matters.

Manchón, R. M. (In press a). The language learning potential of writing in foreign language contexts. Lessons from research. En M. Reichelt \& T. Chimasko (Eds.), Foreign Language Writing. Research insights. West Lafayette: Parlour Press.

Manchón, R. M. (In press b). Writing to learn the language: Issues in theory and research. En R. M. Manchón (Ed.), Learning to write and writing to learn in an additional language. Amsterdam: John Benjamins.

Manchón, R. M., Murphy, L. \& Roca de Larios, J. (2007). Lexical retrieval processes and strategies in second language writing: A synthesis of empirical research. International Journal of English Studies, 2, 149-174. 
Manchón, R. M. \& Roca de Larios, J. (2007). Writing-to-learn in Instructed Language Learning Contexts. In E. Alcón Soler \& M. P. Safont Jordá (Eds.), Intercultural Language Use and Language Learning (pp. 101-121). Dordrecht: Springer.

Muranoi, H. (2007). Output practice in the L2 classroom. In R. DeKeyser (Ed.), Practice in a second Language: Perspectives from applied linguistics and cognitive psychology (pp. 51-84). Cambridge: Cambridge University Press.

Niu, R. (2009). Effect of task-inherent production modes on EFL learners' focus on form. Language Awareness, 18, 384-402.

Norris, J. M., \& Ortega, L. (2000). Effectiveness of L2 instruction: A research synthesis and quantitative meta-analysis. Language Learning, 50, 417-528.

Plakans, L. (2009). The role of reading strategies in integrated L2 writing tasks. Journal of English for Academic Purposes, doi:10.1016/j.jeap.2009.05.001.

Polio, C. \& Williams, J. (2009). Teaching and testing writing. In M. Long \& C. Doughty (Eds.), The handbook of language teaching (pp. 486-555). Wiley-Blackwell.

Qi, D. S. \& Lapkin, S. (2001). Exploring the role of noticing in a three-stage second language writing task. Journal of Second Language Writing, 10, 277-303.

Reinders, H. (2009). Learner uptake and acquisition in three grammar-oriented production activities. Language Teaching Research, 13, 201-222.

Robinson, P. (1995). Attention, memory and the "noticing” hypothesis. Language Learning, 45, 283331.

Sachs, R. \& Polio, C. (2007). Learners' uses of two type of written feedback on a L2 writing revision task. Studies in Second Language Acquisition, 29, 1, 67-100.

Santos, M., López Serrano, S. \& Manchón, R. (2010). The differential effects of two types of direct griten corrective feedback on noticing and uptake: Reformulation vs. error correction. International Journal of English Studies, 10, 131-154.

Schmidt, R. (2001). Attention. In P. Robinson (Ed.), Cognition and Second Language Instruction (pp. 3-32). Cambridge: Cambridge University Press.

Schmidt, R. \& Frota, S. (1986). Developing basic conversational ability in a second language: A case study of an adult learner of Portuguese. In R. Day (Ed.), Talking to learn: Conversational in second language acquisition (pp. 237-326). Rowley, MA: Newbury House.

Shehadeh, A. (2001). Self- and other-initiated modified output during task-based interaction. TESOL Quarterly, 35, 433-457.

Shehadeh, A. (2002). Comprehensible Output, From Occurrence to Acquisition: An Agenda for Acquisitional Research. Language Learning, 52, 597-647.

Shi, L. (2004). Textual borrowing in second-language writing. Written Communication, 2, 171-200.

Storch, N. (1999). Are two heads better than one? Pair work and grammatical accuracy. System 27, 363-374.

Storch, N. (2002). Patterns of interaction in ESL pair work. Language Learning, 52, 119-158.

Storch, N. (2005). Collaborative writing: product, process, and students' reflections. Journal of Second Language Writing, 14, 153- 173.

Storch, N. (2007). Investigating the merits of pair work on a text editing task in ESL classes. Language Teaching Research, 11, 143-159.

Storch, N. (2008). Metatalk in a pair work activity: Level of engagement and implications for language development. Language Awatreness, 17, 95-114.

Storch, N. \& Wigglesworth, G. (2007). Writing tasks: The effect of collaboration. In M.P. García Mayo (Ed.), Investigating Tasks in Foreign Language Learning (pp. 157-177). Clevedon, UK: Multilingual Matters.

Storch, N. \& Wigglesworth, G. (2010). Learners' processing, uptake and retention of corrective feedback on writing. Studies in Second Language Acquisition, 32, 303-334.

Swain, M. (1985). Communicative competence: Some roles of comprehensible input and comprehensible output in its development. In S. M. C. Gass, \& C. G. Madden (Eds.), Input in second language acquisition (pp. 235-253). Rowley, MA: Newbury House.

Swain, M. (1995). Three functions of output in second language learning. In G. Cook, \& B. Seidhofer (Eds.), Principles and practice in applied linguistics (pp. 125-144). Oxford: Oxford University Press. 
Swain, M. (1998). Focus of form through conscious reflection. In C. Doughty, \& J. Williams (Eds.), Focus on form in classroom second language acquisition (pp. 64-81). Cambridge: Cambridge University Press.

Swain, M. (2000). The output hypotheses and beyond: Mediating acquisition through collaborative dialogue. In J. Lantolf (Ed.) Sociocultural Theory and Second Language Learning (pp. 97114). Oxford: Oxford University Press.

Swain, M. (2006). Languaging, agency and collaboration in advanced second language proficiency. In H. Byrnes (Ed.), Advanced Language Learning. The Contribution of Halliday and Vygotsky (pp. 95-108). London: Continuum.

Swain, M. \& Lapkin, S. (1995). Problems in output and the cognitive processes they generate: A step towards second language learning. Applied Linguistics, 16, 371-391.

Swain, M. \& Lapkin, S. (2002). Talking it through: Two French immersion learners' response to formulation. International Journal of Educational Research, 37, 285-304.

Tocalli-Beller, A. \& Swain. M. (2005). Reformulation: The cognitive conflict and L2 learning it generates. International Journal of Applied Linguistics 15, 5-28.

Tomlin, R. S. \& Villa, V. (1994). Attention in cognitive science and second language acquisition. Studies in Second Language Acquisition, 16, 183-203.

Truscott, J. (1996). The case against grammar correction in L2 writing classes. Language Learning, 46, 337-343.

Truscott, J. (2004). Evidence and conjecture on the effects of correction: a response to Chandler. Journal of Second Language Writing, 13, 337-343.

Watanabe, Y. \& Swain, M. (2009). Perception of learner proficiency: Its impact on the interaction between an ESL learner and her higher and lower proficiency partners. Language Awareness 17, 115-130.

Wigglesworth, G. \& Storch, N. (2009). Pair versus individual writing: Effects of fluency, complexity and accuracy. Language Testing 26, 45-466.

Williams, J. (2001). Learner-generated attention to form. In R. Ellis (Ed), Form-focused instruction and second language learning (pp. 303-346). Malden, MA: Blackwell.

Zhang, S. (1995). Re-examining the affective advantage of peer feedback in the ESL writing class. Journal of Second Language Writing, 4, 209-222.

Zhao, H. (2010). Investigating learners' use and understanding of peer and teacher feedback on writing: a comparative study in a Chinese English writing classroom. Assessing Writing, 15, 317. 
APPENDIX A: THE PICTURE PROMPT

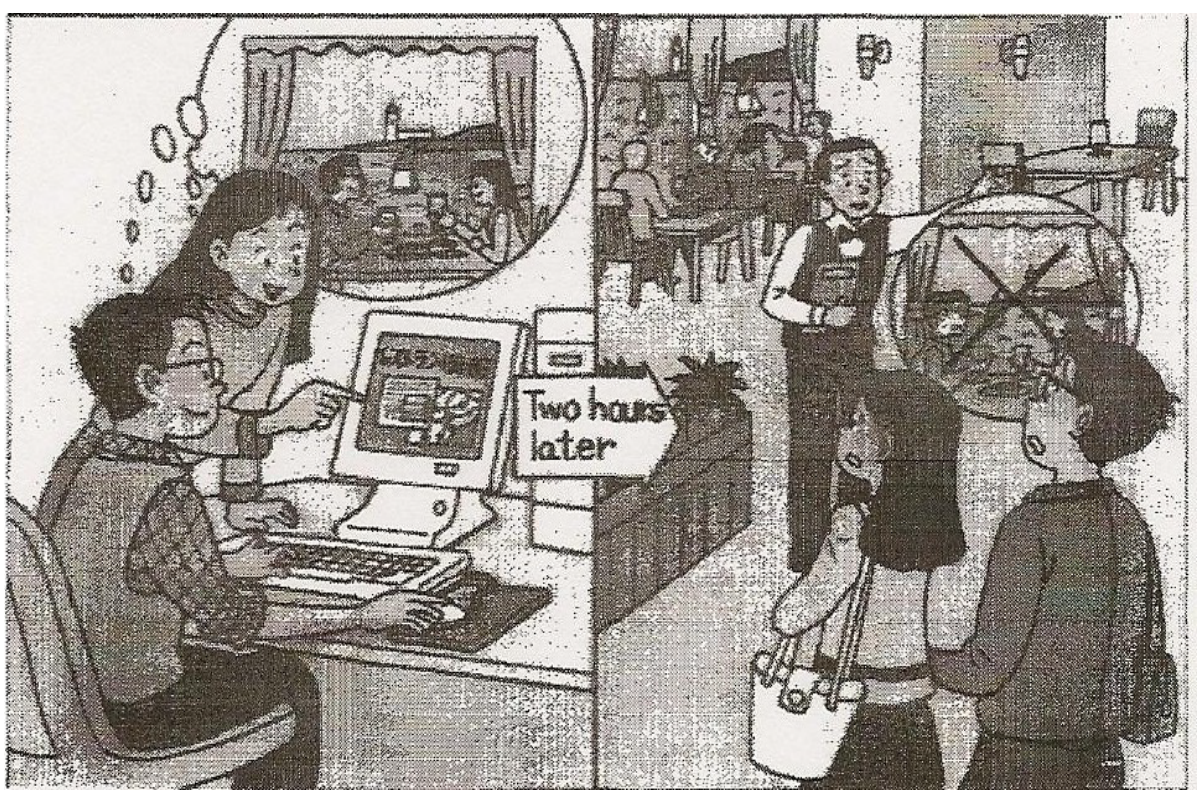

From the EIKEN Test in Practical English Proficiency, Grade 2. Produced and administered by the Society for Testing English Proficiency (STEP), Inc.

Used with permission. 


\section{APPENDIX B: THE NATIVE SPEAKER MODELS}

\section{Model A}

One day a young couple were checking out restaurant information on the Internet. They found a nice restaurant that had tables next to large windows overlooking the ocean. The view looked great, so they decided to go. Two hours later, they arrived at the restaurant and found that all the window tables were taken. A waiter showed them a table in an isolated corner that had no view at all. They were very shocked and disappointed.

\section{Model B}

Last Sunday my husband and I were trying to find a nice restaurant where we could get a good view of the sea. The reason was that it was our $10^{\text {th }}$ anniversary on Sunday. After checking the Internet for about an hour, we found an ideal restaurant.

Two hours later, we arrived there, but found it was so crowded that we couldn't get a table by the window. Disappointed, we decided not to eat there and went back home.

Taken from Hanaoka (2006). Used with permission. 